\title{
Simultaneous Determination of Fish Steroidal Hormones using RP-HPLC with UV Detection by Multi-step Gradient Elution Technique
}

\author{
Ningthoukhongjam Soranganba* and I.J. Singh \\ Department of Fisheries Resource Management, College of Fisheries \\ G.B.P.U.A \& T, Pantnagar, Uttarakhand, India - 263145
}

A B S T R A C T

Keywords

RP-HPLC,

Testosterone,

$17 \beta$-estradiol, $17 \alpha$,

20ß-dihydroxy-4-

pregnen-3-one

(DHP), Cortisol,

amur carp, Multi-

step gradient

Article Info

Accepted:

15 January 2018

Available Online:

10 February 2018
A reversed phase high performance liquid chromatography (HPLC) method with UV detection by multi-step gradient elution method has been developed for simultaneous determination of testosterone, 17 $\beta$-estradiol, 17 $\alpha$, 20 $\beta$-dihydroxy-4pregnen-3-one and cortisol in fish. The method described includes limited sample preparation with single step SPE using $\mathrm{C}_{18}$ cartridge. A multi-step gradient elution of water $(\mathrm{A})$ and acetonitrile (B) with flow rate $1-1.5 \mathrm{ml} / \mathrm{min}$ with curve index 5 of $20 \%$ to $80 \%$ of B at various intervals and variable detection at UV max of $203 \mathrm{~nm}$ and $242 \mathrm{~nm}$. Validation of the method was performed in terms of recovery with 87.2-106\%, intra- and inter-assay variability of $0.93-21.28 \%$ and $0.40-9.18 \%$ respectively and linearity between $10-1200 \mathrm{ng} / \mathrm{ml}$. E2 shows the least LOD $(25.16 \mathrm{ng} / \mathrm{ml})$ and LOQ $(229.8 \mathrm{ng} / \mathrm{ml})$ followed by cortisol $(45.64 \mathrm{ng} / \mathrm{ml}$ and $138.32 \mathrm{ng} / \mathrm{ml}) \mathrm{T}(72.946 \mathrm{ng} / \mathrm{ml}$ and $221.04 \mathrm{ng} / \mathrm{ml})$ and DHP $(75.83 \mathrm{ng} / \mathrm{ml}$ and $138.32 \mathrm{ng} / \mathrm{ml})$. The developed chromatograph was applied to analyse plasma hormonal level in amur carp.

\section{Introduction}

The reproductive biomarkers like sex steroid hormone (viz. testosterone, 17 $\beta$-estradiol), maturation inducing hormone $(17 \alpha, 20 \beta$ dihydroxy-4-pregnen-3-one or DHP) and stress hormone (cortisol) were important indicators which elucidate the reproduction and physiological status of the fish, thus playing a cascading effect and feedback mechanism. Fish testes synthesize testosterone (T), androstenedione and 11ketotestosterone (11-KT) (Wei-xin, 1998) among which the role of $\mathrm{T}$ and 11-KT on fish reproduction have been much discussed including maturation of gonads, development of secondary sexual characters and induction of reproductive behaviour (Matty, 1985) with $\mathrm{T}$ having effect on some spermatogenesis pathways like spermatogonial multiplication and spermatocyte formation (Billard et al., 1982; Gazolla and Borella, 1997). T released from the body in the form of metabolic waste product, like urine, act as sex pheromone attracting opposite sex and affects sexual behaviour (Fostier, 1983). Also, it is equally 
important in both male and female counterpart as a precursor of estrogenic biosynthesis implicating female reproductive processes. Association of estrogenic hormones with reproductive cycle by means of co-ordinating the female reproductive effort to yield maximum success is a classic model known for reproduction system wherein ova production, steroid hormones and sexual behaviours come together (Crews, 1984). Despite $\mathrm{T}$ and 11-KT being male specific hormones, they are also present in female (Slater et al., 1994) even though the role of $\mathrm{T}$ in female has not been clear other than the effect in maintaining the release and surge of GtHs in some species (Fostier et al., 1983; Kobayashi et al., 1988). E2 produce from $\mathrm{T}$ leads to the production of vitellogenin, a yolk pre-cursor, which are further deposited in the oocyte in the process through vitellogenesis (Lee and Yang, 2002) and controlled the increase in the ovarian size during final oocyte maturation (Adebiyi et al., 2013). The progestin, DHP act as an important facilitator in biosynthetic pathways of various steroidal hormones both in the form of reproduction and/or augmenting it as chemical stimulants. Glucocorticoid is related to stress and have detrimental effect on the key production issues including reproduction (Pickering, 1992). Cortisol plays a regulatory role in many important physiological processes and elevated plasma cortisol levels are thought to affect physiological functions leading to adverse impacts on traits such as growth, disease resistance and reproductive output (Lankford and Weber, 2006) because stress is thought to supress reproductive physiology via a wide range of mechanisms (Schreck, 2010). Thus, the cortisol induced impairment of growth may directly affect reproductive output since reproduction is linked to body size (Ellis et al., 2012).

High performance liquid chromatography or high pressure liquid chromatography is a popular analytical technique for separation, identification and quantification of individual constituent mixture (Sultan, 2016). Iwasaki et al., (2012) reviewed HPLC and RP-HPLC as an indispensable tool most widely used for analytical techniques and edge over others in terms of ability to retain and resolve many biological compounds. The method involving RP-HPLC with UV detection and isocratic and gradient elution were most commonly used technique for biological studies (Navajas et al., 1995; Sanwald et al., 1995; $\mathrm{Ng}$ and Yuen, 2003; Samanidou et al., 2007)

The aim of the present study was to develop and validate a simple HPLC method of multistep gradient elution and determining UV (max) response for rapid, accurate, and sensitive determination of four steroidal reproductive fish hormones testosterone, $17 \beta$ estradiol, cortisol and $17 \alpha, 20 \beta$-dihydroxy-4pregnen-3-onesimultaneouslyin fish (amur carp).

\section{Materials ad Methods}

All chemicals and reagents used during the experiments were of analytical and HPLC grade. Testosterone (Fig. 1) CAS no. 58-22-0, purity $\geq 99.0 \%$, $\beta$-estradiol (Fig. 2) CAS no. 50-28-2, purity $\geq 98.0 \%$, hydrocortisone (Fig. 3) CAS no. 50-23-7, purity $\geq 98.0 \%$ and $17 \alpha$, 20ß-dihydroxy-4-pregnen-3-one (Fig. 4) crystalline CAS no. 1662-06-2 were purchased from Sigma-Aldrich, India. HPLC grade solvent used for mobile phase, sample solvent and system maintenance includes water (SRL and Hi-media) methanol and acetonitrile (Merck), isopropanol (SRL) and diethyl ether (CDH).2 ml auto sampler vials and closures (Borosil), syringe driven PTFE hydrophobic filter of $0.22 \mu \mathrm{m} 13 \mathrm{~mm}$ dia. (Hi-media), solid phase extractor (SPE) cartridge [119855] (Lichrolut RP-18 40-63 $\mu \mathrm{m} 100 \mathrm{mg} 1 \mathrm{ml}$ standard PP-tubes) (Merck, Germany), normal $2 \mathrm{ml}$ and $5 \mathrm{ml}$ sterile syringe 
and plasma tubes (lithium heparin coated) $3 \mathrm{ml}$ tubes (without vacuum) were used.

\section{HPLC instrument and chromatographic conditions}

The method was developed on a Dionex Ultimate 3000 HPLC fully automated by Chromeleon 6.8 software equipped with binary gradient pump (HPG-3200A) having flow rate range of $0.001-10 \mathrm{ml} / \mathrm{mins}$ with accuracy of $\pm 0.1 \%$ at $1 \mathrm{ml} / \mathrm{mins}$, precision of $<0.1 \% \mathrm{RSD}$ at $1 \mathrm{ml} / \mathrm{mins}$, pressure range of 7250 psi, pressure ripple of $<1 \%$ and proportioning accuracy of $\pm 0.2 \%$. Solvent rack [5035.9250] SR-3200 with degasser channels. Auto Sampler [6822.0010] WPS3000SL with injection method of in-line split loop, injection volume of $1-90 \mu$ l (settable at $0.1-100 \mu 1)$, injection volume accuracy of $\pm 0.5 \%$ at 50 and $90 \mu 1$, injection volume precision of $0.3 \% \mathrm{RSD}$ at $5 \mu 1$, linearity of > $0.999, \mathrm{RSD}<0.5 \%$ at $5-80 \mu 1$, sample carry over of $<0.005 \%$ (for caffeine) with external wash and injection cycle time of $<15 \mathrm{~s}$ for $5 \mu 1$. Thermostatic column compartment TCC-3000 [5722.0000] with temperature range of $5^{0} \mathrm{C}$ to $85^{\circ} \mathrm{C}$, temperature accuracy of $\pm 0.5^{\circ} \mathrm{C}$, temperature stability of $\pm 0.1^{0} \mathrm{C}$, temperature precision of $\pm 0.1^{0} \mathrm{C}$. UV/VIS VWD-3400 detector with variable wavelength detector can monitor samples at four different wavelengths using double beam forward optics design from Deuterium and Tungsten lamp, noise typically $< \pm 2.5 \mathrm{x} \mu \mathrm{AU}$ at $254 \mathrm{~nm}$, drift $<0.1 \mathrm{mAU} / \mathrm{hr}$ at $254 \mathrm{~nm}$, linearity upto 2.5AU, wavelength ranging from 190-900 nm with band width of $6 \mathrm{~nm}$ at $254 \mathrm{~nm}$ and data collection rate of $100 \mathrm{~Hz}$. The chromatographic separation was achieved using Purospher STAR RP-18 encapped (3 $\mu \mathrm{m})$ Hibar 100-4.6mm [HX61192969] column along with Chromolith RP-18e 5 4.6mm [HX68773851] guard cartridge and guard cartridge holder [HX72199332] using water and acetonitrile as mobile phase $\mathrm{A}$ and
B respectively. UV detection of the analyte were simultaneously carried out and scanned at different UV at $203 \mathrm{~nm}, 220 \mathrm{~nm}, 242 \mathrm{~nm}$, $254 \mathrm{~nm}$ to determine the best peak resolution considering the UV max of $17 \beta$-estradiol (203nm and $281 \mathrm{~nm}$ ) (Cayman product info 10006315; Yilmaz and Kadioglu 2017), testosterone (241nm and 242nm) (Cayman product info 15645; Sigma product info T5411), cortisol (242nm) (Lang, 1961; Sigma product info H5885; Cayman product info 20739) and DHP (242nm) (Cayman product info. 16146).

A multi-step gradient flow of $100 \%$ water (A) and 100 acetonitrile $(\mathrm{B})$ with $\% \mathrm{~B}$ starting at 20\% - 50\% for 3.5mins@1ml/min; 3.5-4.5 mins@1.5ml/min at $50 \% \mathrm{~B}$; 4.5-5.0 mins @1 $\mathrm{ml} / \mathrm{min}$ at $50 \% \mathrm{~B} ; 5.0-6.5 \mathrm{mins} @ 1 \mathrm{ml} / \mathrm{min}$ at $60 \% \mathrm{~B}$ till 7.5mins; 7.5-8.5mins@1ml/min at $80 \% \mathrm{~B}$ till $9.5 \mathrm{~min}$ and back to $20 \% \mathrm{~B}$ @ $1 \mathrm{ml} / \mathrm{min}$ at 10 mins. All the gradient use curve index of 5. Data acquisition was selected from 2 mins till the end.

\section{Maintenance and optimisation HPLC system}

Washing initiate by priming syringe 3-5 times using 80:20\% (IPA: water), wash buffer loop and external needle with $300 \mu \mathrm{l}$ and $100 \mu \mathrm{l}$ IPA solution respectively. Purge pump for both the solvent line $\mathrm{A}$ and $\mathrm{B}$ with system programmed draw speed (@5ml/mins). Set column compartment temperature to the desire temperature $\left(30^{\circ} \mathrm{C}\right)$ and UV detector at different wavelengths of $203 \mathrm{~nm}, 220 \mathrm{~nm}$, $242 \mathrm{~nm}$ and $254 \mathrm{~nm}$. Check data acquisition baseline for normal system stability and run for 30 to $45 \mathrm{mins}$ before every analysis.

\section{Methodology and sample preparation Sampling and blood collection}

Hatchery breed amur carp were collected and maintained in experimental earthen pond 
College of Fisheries, GBPUAT, Pantnagar. The experimental site is located in Tarai region of Shivalik range of the Himalayas having sub-tropical climatic condition characterized by very hot, humid and dry summer and very cold winter with monsoon falling between mid of June till the end of September. Clove oil (Velisek et al., 2005) was used to anaesthetise prior to regular handling or experimental procedure. Blood were drawn from the caudal vein using a sterile $2 \mathrm{ml}$ syringe immediately within 5 minutes and dispensed into non-vacuum lithium heparin pre-coated tubes. The heparinised blood were centrifuged at $10,000 \mathrm{rpm}(11180 \mathrm{x} \mathrm{g})$ for $12 \mathrm{mins}$ at $4^{0} \mathrm{C}$ and the supernatant were collected in $2 \mathrm{ml}$ micro centrifuge tubes and analysed immediately or stored at below $-20^{\circ} \mathrm{C}$ sealed with parafilm till further analysis.

\section{Preparation of stock solution}

Dissolved 1mg of individual pure solutes (steroid hormones) in 10ml HPLC grade methanol after weighing up to the last decimal and labelled. Prepare appropriate dilution of the individuals working solutions using acetonitrile (mobile solvent) from the stock solution to obtain concentrations between 10 $1200 \mu \mathrm{g} / \mathrm{ml}$ and stored at below $4^{0} \mathrm{C}$ until use.

\section{Sample pre-treatment}

Pre-treated each aliquot with SPE by prewetting the SPE bed using $400 \mu \mathrm{l}$ methanol followed by $400 \mu 1$ water. Load sample into the SPE tubes and washed with $10 \%$ methanol. Maintain faster flow rate of 1-2 drops per seconds for the above procedures. Then elute the sample eluted with methanolin 3 phase using $200 \mu \mathrm{l}$ twice and $100 \mu 1$ to get maximum recovery by gravity. Before loading, filter the samples with $0.2 \mu \mathrm{m} 13 \mathrm{~mm}$ PTFE hydrophobic syringe filter directly into the auto sampler vials and closure.

\section{Assay validation}

Assay validation was carried out by analysing the response peak against the known concentration using regression analysis. Recovery of an analyte was determined in order to validate the methodology and accuracy of the assay.

The recovery percentage was calculated as 100 response/standard concentration. Thus, the accuracy of the method was given as SD of recovery percent. Limit of Detection (LOD) calculated was based on the SD of yintercepts of regression analysis $(\sigma)$ and the slope (S), using the following equation LOD $=3.3 \mathrm{\sigma} / \mathrm{S}$. Limits of quantitation (LOQ) was calculated using equation $\mathrm{LOQ}=10 \sigma / \mathrm{S}$.

\section{Results and Discussion}

\section{Validation and quantitation of the assay}

The following criteria were followed in order to validate the analytical procedure viz. linearity, sensitivity, recovery, accuracy, LOD and LOQ (Table 1).

\section{Linearity}

The linearity of the assay were observed in different concentration ranging from 10 to $1200 \mathrm{ng} / \mathrm{ml}$ for T, DHP and cortisol and from 50 to $1200 \mathrm{ng} / \mathrm{ml}$ for E2 by plotting a calibration curves of the best fit using linear regression analysis. The correlation coefficient (r) of T, E2, DHP and cortisol were $0.9994,0.9998,0.9995$ and 0.9998 respectively.

\section{Accuracy}

The accuracy of the assay was determined by assessing the recovery percentage of the steroid hormones in different concentrations. DHP shows maximum accuracy of $106 \%$ 
followed by cortisol (95.16\%), T (93.2\%) and E2 (87.27\%) respectively.

\section{Stability, repeatability and precision}

The stored standard solutions and the sample extract below $-20^{\circ} \mathrm{C}$ were checked for peak results and retention time. The intra- and inter-assay chromatography variations for cortisol, DHP and T observed at UV max of
$242 \mathrm{~nm}$ and $\beta$-estradiol at $203 \mathrm{~nm}$ were determined from three and five replicates respectively. The average retention time $\pm \mathrm{SD}$ of the hormones and percent co-efficient were shown in Table 2. Negligible change was observed in the retention time. $\mathrm{T}$ and $\mathrm{E} 2$ shows very minute percent change in peak area (mAU) followed by DHP while cortisol shows higher intra (21.28\%) and inter $(9.18 \%)$ variations.

Table.1 Assay validity sheet for T, E2, DHP and cortisol

\begin{tabular}{|l|l|c|c|c|c|}
\hline Sl. & Parameters & T & E2 & DHP & Cortisol \\
\hline $\mathbf{1}$ & $\mathrm{n}$ & 8 & 7 & 8 & 8 \\
\hline $\mathbf{2}$ & Slope & 0.0006 & 0.001 & 0.0004 & 0.0004 \\
\hline $\mathbf{3}$ & Intercept & 0.0152 & 0.009 & 0.0052 & 0.0021 \\
\hline $\mathbf{4}$ & SE of intercept & 0.00468 & 0.00341 & 0.00325 & 0.00195 \\
\hline $\mathbf{5}$ & SD of intercept & 0.01326 & 0.00762 & 0.00726 & 0.00437 \\
\hline $\mathbf{6}$ & Linearity range (ng) & $10-1200$ & $50-1200$ & $10-1200$ & $10-1200$ \\
\hline $\mathbf{7}$ & Correlation coefficient (r) & 0.9994 & 0.9998 & 0.9995 & 0.9998 \\
\hline $\mathbf{8}$ & Accuracy & $93.2 \pm 19.02$ & $87.27 \pm 16.3$ & $106 \pm 6.56$ & $95.16 \pm 8.49$ \\
\hline $\mathbf{9}$ & LOD & 72.946 & 25.162 & 75.83 & 45.64 \\
\hline $\mathbf{1 0}$ & LOQ & 221.04 & 76.24 & 229.8 & 138.32 \\
\hline
\end{tabular}

Table.2 Intra- and Inter-assay variation and retention time

\begin{tabular}{|c|l|c|c|c|c|}
\hline \multicolumn{2}{|c|}{ Hormones } & Cortisol & E2 & DHP & T \\
\hline \multicolumn{2}{|c|}{ Rt (min) } & $4.129 \pm 0.004$ & $6.339 \pm 0.004$ & $6.647 \pm 0.003$ & $6.85 \pm 0.008$ \\
\hline $\begin{array}{c}\text { Peak } \\
\text { Area } \\
(\mathbf{m A U})\end{array}$ & Intra & $21.28 \%$ & $1.61 \%$ & $4.77 \%$ & $0.93 \%$ \\
\cline { 2 - 6 } & Inter & $9.18 \%$ & $1.50 \%$ & $4.55 \%$ & $0.48 \%$ \\
\hline
\end{tabular}<smiles>C[C@]12CCC(=O)C=C1CC[C@@H]1[C@@H]2CC[C@@]2(C)[C@@H](O)CC[C@@H]12</smiles>

Fig.1 Testosterone (T)<smiles>C[C@]12CCC3c4ccc(O)cc4CC[C@H]3[C@@H]1CC[C@@H]2O</smiles>

Fig.2 17ß-Estradiol (E2) 


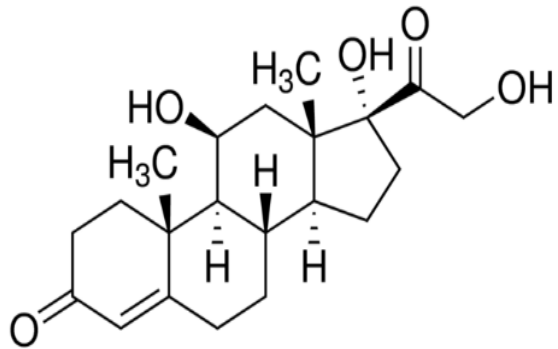

Fig.3 Hydrocortisone (cortisol)

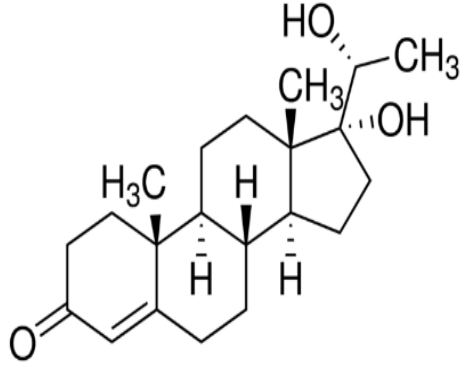

Fig.4 17 $\alpha$, 20ß-Dihydroxy-4-pregnen-3-one (DHP)

Fig.5 Chromatogram of male and female plasma. (a) and (b) represent pre-spiked and postspiked female; (c) and (d) represent pre-spiked and post-spiked male with $600 \mathrm{ng} / \mathrm{ml}$ of standards.

Peak 1, 2, 3 and 4 represents cortisol, E2, DHP and T respectively. Row 1, 2 and 3 shows the peak response at $203 \mathrm{~nm}+242 \mathrm{~nm}$ (overlay), 203nm and $242 \mathrm{~nm}$ wavelength

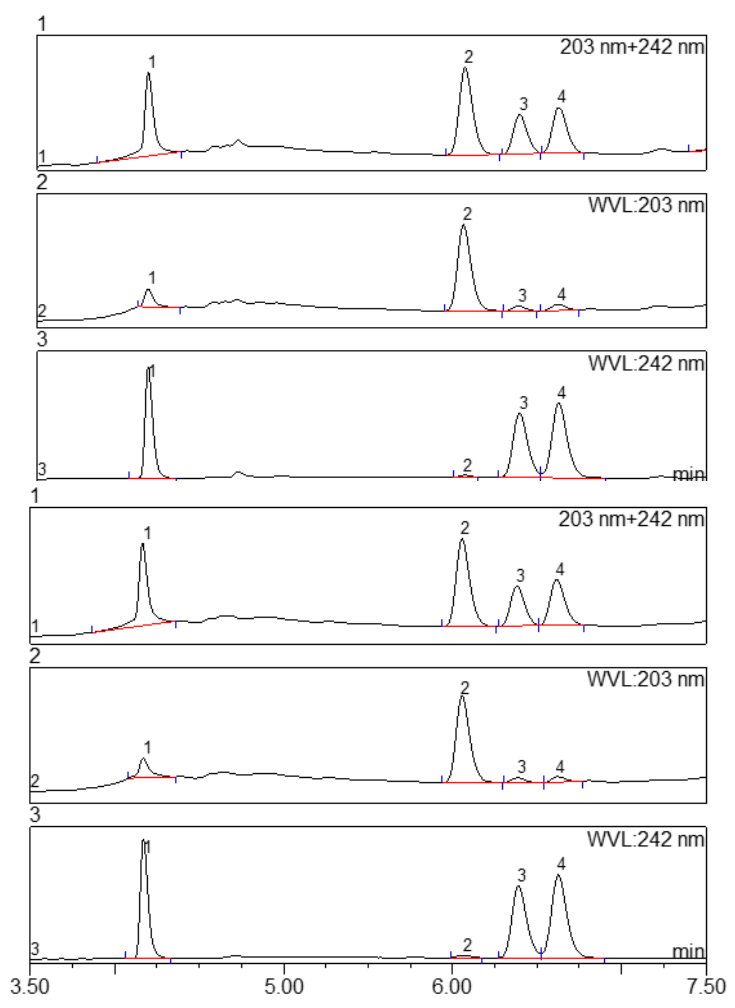

Limit of Detection (LOD) and Limit of Quantification (LOQ)

The LOD and LOQ determined using above formula. The detection limit of the method was calculated as $72.9 \mathrm{ng} / \mathrm{ml}$ for $\mathrm{T}$, $25.16 \mathrm{ng} / \mathrm{ml}$ for E2, 75.83ng/ml for DHP and $45.64 \mathrm{ng} / \mathrm{ml}$ for cortisol. The limit of quantification which provide the lower

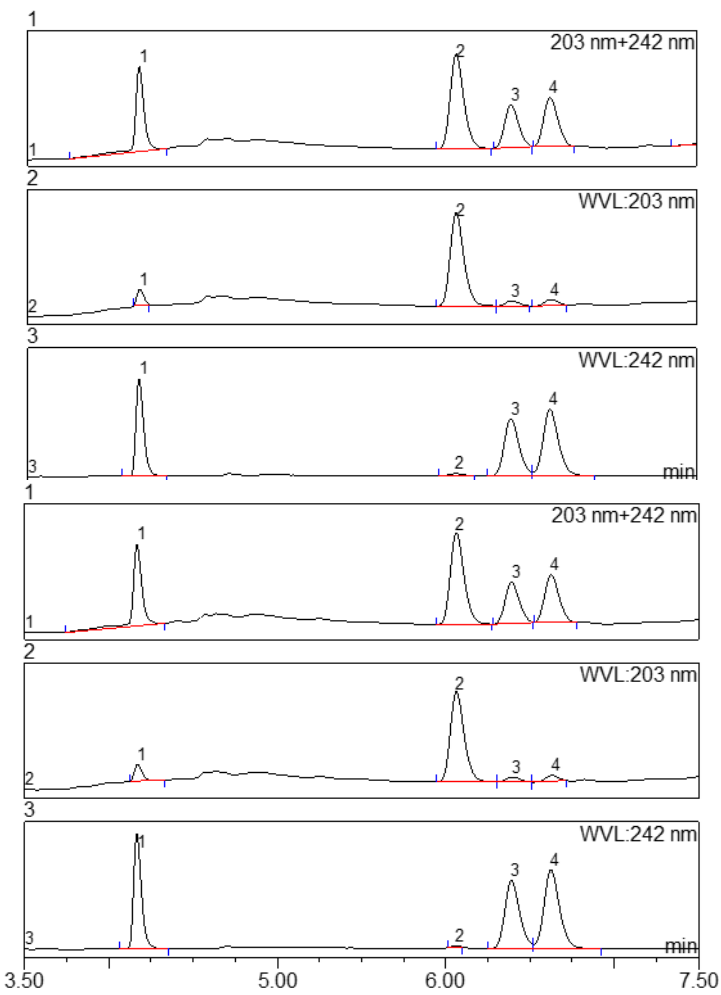

concentration at which the method can be repeated were $221.04 \mathrm{ng} / \mathrm{ml}$ for T, $76.24 \mathrm{ng} / \mathrm{ml}$ for E2, 229.8ng/ml for DHP and $138.32 \mathrm{ng} / \mathrm{ml}$ for cortisol.

\section{Application of the proposed assay protocol}

Reproduction related steroidal hormones of male and female of Cyprinus carpio 
haematopterus were analysed using the chromatographic conditions described above after spiking the plasma sample with known concentrations of $600 \mathrm{ng} / \mathrm{ml}$ of the standards. Spiking concentration is important considering the LOD and LOQ of the HPLC. The chromatogram of male and female plasma indicating pre-spiked and post-spiked conditions were shown in Figure 5 at UV max of $242 \mathrm{~nm}$ for T, DPH and cortisol whereas E2 shows maximum response at $203 \mathrm{~nm}$. A comparative representation of the combined UV i.e. $203 \mathrm{~nm}+242 \mathrm{~nm}$ (overlay) has been in cooperated using software to simultaneously determine the peak responses of all the four hormones.

Hence concluded, in the present study, a simple multi-step gradient elution HPLC method has been develop to identify and quantify steroidal hormone for fish with maximum UV response. The use of RP column with variable UV detection enables rapid and sensitive analysis. Thus, the proposed chromatographic condition and detection limits were proved to be effective and convenient for steroidal hormones related to fish reproductive studies.

\section{References}

Adebiyi, F.A., Siraj, S.S., Harmin, S.A. and Christianus, A. 2013. Plasma sex steroid hormonal profile and gonad histology during the annual reproductive cycle of river catfish Hemibagrus nemurus (Valenciennes, 1840) in captivity. Fish physiology and biochemistry, 39(3): 547-557.

Billard, R., Fostier, A., Weil, C. and Breton, B. 1982. Endocrine control of spermatogenesis in teleost fish. Canadian Journal of Fisheries and Aquatic Sciences, 39(1): 65-79

Crews, D. 1984. Gamete production, sex hormone secretion, and mating behavior uncoupled, Horm. Behav. 18: 22-28

Ellis, T., Yildiz, H.Y., López-Olmeda, J., Spedicato, M.T., Tort, L., Øverli, Ø. and Martins, C.I. 2012. Cortisol and finfish welfare. Fish physiology and biochemistry, 38(1): 163-188.

Fostier, A., Jalabert, B., Billard, R., Breton, B. and Zohar, Y. 1983. The Gonadal Steroids. Fish physiology, 9: 277-372.

Gazola, R., and Borella, M. I. 1997. Plasma testosterone and 11-ketotestosterone levels of male pacu Piaractus mesopotamicus (Cypriniformes, Characidae). Brazilian Journal of Medical and Biological Research, 30: 1485-1487.

Iwasaki, Y., Sawada, T., Hatayama, K., Ohyagi, A., Tsukuda, Y., Namekawa, K. and Nakazawa, H. 2012. Separation technique for the determination of highly polar metabolites in biological samples. Metabolites, 2(3): 496-515.

Kobayashi, M.; Aida, K.; Hanyu, I., 1988. Hormone changes during the ovulatory cycle in goldfish. General and Comparative Endocrinology, 69: 301307

Láng, L. 1961. Absorption spectra in the ultraviolet and visible region.

Lankford, S. and Weber, G. 2006. Potential roles of intraovarian growth factors during follicle maturation in rainbow trout (Oncorhynchus mykiss) (Meeting Abstract)

Lee, W.K. andYang, S.W. 2002. Relationship between ovarian development and serum levels of gonadal steroid hormones and induction of oocyte maturation and ovulation in the cultured female Korean spotted sea bass Lateolabrax maculatus (Jeomnongoeo). Aquaculture 207:169-183

Matty, A.J., 1985. Gonadal Hormones. In "Fish endocrinology"pp138-173. Croom Helm Ltd., London.

Navajas, R., Imaz, C., Carreras, D., García, 
M., Pérez, M., Rodríguez, C., and Cortés, R. 1995. Determination of epitestosterone and testosterone in urine by high-performance liquid chromatography. Journal of Chromatography B: Biomedical Sciences and Applications, 673(2): 159164.

Navajas, R., Imaz, C., Carreras, D., García, M., Pérez, M., Rodríguez, C., and Cortés, R. 1995. Determination of epitestosterone and testosterone in urine by high-performance liquid chromatography. Journal of Chromatography B: Biomedical Sciences and Applications, 673(2): 159164.

Ng, B. H., and Yuen, K. H. 2003. Determination of plasma testosterone using a simple liquid chromatographic method. Journal of Chromatography B, 793(2): 421-426.

Pickering, A.D. 1992. Rainbow trout husbandry: management of the stress response. Aquaculture, 100(1-3): 125139.

Samanidou, V. F., Karageorgou, E. G., and Papadoyannis, I. N. 2007. Simultaneous determination of testosterone and its major metabolite epitestosterone in biological fluids by HPLC. Journal of liquid chromatography and related technologies, 30(9-10): 1317-1331.

Sanwald, P., Blankson, E. A., Duléry, B. D., Schoun, J., Huebert, N. D., and Dow, J. 1995. Isocratic high-performance liquid chromatographic method for the separation of testosterone metabolites. Journal of Chromatography B: Biomedical Sciences and Applications,
672(2): 207-215.

Schreck, C.B. 2010. Stress and fish reproduction: the roles of allostasis and hormesis. General and comparative endocrinology, 165(3): 549-556.

Slater, C. H., Schreck, C. B. and Swanson, P. 1994. Plasma profiles of the sex steroids and gonadotropins in maturing female spring Chinook salmon (Oncorhynchus tshawytscha). Comp. Biochem. Physiol. 109A: 167-175

Sultana, T. 2016. Instrumental detection of lipid accumulation in Nannochloris eukaryotum resulting from nitrogen deprivation. Villanova University.

Velisek, J., Svobodova, Z., Piackova, V., Groch, L., and Nepejchalova, L. 2005. Effects of clove oil anaesthesia on common carp (Cyprinus carpio L.). Vet Med, 50(6): 269-275.

Wei-xin, Zhao. 1990. Testosterone and 11oxotestosterone changes during an annual cycle and induced spawning in blunt snout bream (Megalobrama amblycephala). Fish Physiology, Fish Toxicology, and Fisheries Management: Proceedings of an International Symposium, Guangzhou, PRC, September 14-16, 1988. Environmental Research Laboratory, Office of Research and Development, US Environmental Protection Agency.

Yilmaz, B., and Kadioglu, Y. 2017. Determination of $17 \beta$-estradiol in pharmaceutical preparation by UV spectrophotometry and high performance liquid chromatography methods. Arabian Journal of Chemistry, 10, S1422-S1428.

\section{How to cite this article:}

Ningthoukhongjam Soranganba and Singh, I.J. 2018. Simultaneous Determination of Fish Steroidal Hormones using RP-HPLC with UV Detection by Multi-step Gradient Elution Technique. Int.J.Curr.Microbiol.App.Sci. 7(02): 1397-1404.

doi: https://doi.org/10.20546/ijcmas.2018.702.168 